This article was downloaded by: [University of Salford]

On: 24 August 2009

Access details: Access Details: [subscription number 910123716]

Publisher Informa Healthcare

Informa Ltd Registered in England and Wales Registered Number: 1072954 Registered office: Mortimer House, 37-41 Mortimer Street, London W1T 3JH, UK

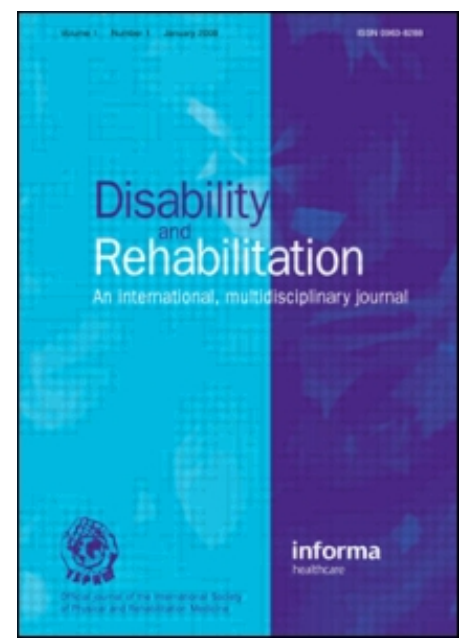

Disability \& Rehabilitation

Publication details, including instructions for authors and subscription information:

http://www.informaworld.com/smpp/title content=t713723807

\title{
What treatment packages do UK physiotherapists use to treat postural control and mobility problems after stroke?
}

S. F. Tyson a; L. A. Connell a; S. Lennon b; M. E. Busse ${ }^{c}$

${ }^{a}$ Centre for Rehabilitation and Human Performance Research, University of Salford, Salford, UK ${ }^{\mathrm{b}}$ Health and

Rehabilitation Sciences Research Institute, University of Ulster, Northern Ireland, UK ${ }^{\mathrm{c}}$ Department of

Physiotherapy, Cardiff University, Cardiff, UK

Online Publication Date: 01 September 2009

To cite this Article Tyson, S. F., Connell, L. A., Lennon, S. and Busse, M. E.(2009)'What treatment packages do UK physiotherapists use to treat postural control and mobility problems after stroke?',Disability \& Rehabilitation,31:18,1494 — 1500

To link to this Article: DOI: $10.1080 / 09638280802627686$

URL: http://dx.doi.org/10.1080/09638280802627686

\section{PLEASE SCROLL DOWN FOR ARTICLE}

Full terms and conditions of use: http://www.informaworld.com/terms-and-conditions-of-access.pdf

This article may be used for research, teaching and private study purposes. Any substantial or systematic reproduction, re-distribution, re-selling, loan or sub-licensing, systematic supply or distribution in any form to anyone is expressly forbidden.

The publisher does not give any warranty express or implied or make any representation that the contents will be complete or accurate or up to date. The accuracy of any instructions, formulae and drug doses should be independently verified with primary sources. The publisher shall not be liable for any loss, actions, claims, proceedings, demand or costs or damages whatsoever or howsoever caused arising directly or indirectly in connection with or arising out of the use of this material. 


\title{
What treatment packages do UK physiotherapists use to treat postural control and mobility problems after stroke?
}

\author{
S. F. TYSON ${ }^{1}$, L. A. CONNELL ${ }^{1}$, S. $\operatorname{LENNON}^{2}$ \& M. E. BUSSE ${ }^{3}$ \\ ${ }^{1}$ Centre for Rehabilitation and Human Performance Research, University of Salford, Salford, UK, ${ }^{2}$ Health and Rehabilitation \\ Sciences Research Institute, University of Ulster, Northern Ireland, UK, and ${ }^{3}$ Department of Physiotherapy, Cardiff University, \\ Cardiff, UK
}

Accepted November 2008

\begin{abstract}
Objective. The aim of this study was to identify the treatment packages (combinations of interventions) used to treat postural control and mobility problems for patients with stroke.

Method. A convenience sample of 74 physiotherapists from 34 National Health Service hospitals recorded the interventions used to treat postural control and mobility problems for 251 patients with stroke in 1156 treatment sessions using the Stroke Physiotherapy Intervention Recording Tool (Tyson and Selley, Disabil Rehabil 2004;26:1184 - 1188). Descriptive statistics assessed the frequency with which the interventions were used and geometric coding indentified treatment packages.

Results. The most frequently used interventions involved facilitation, practice of activities and their components and mobilisations. The least frequently used interventions involved the provision of equipment, teaching carers or professionals and exercise. Two treatment packages were identified; one involving the facilitation (of activities and their components) and the other involving whole activities (facilitation and practice).

Conclusions. Interventions are often combined in two treatment packages to treat postural control and mobility problems after stroke. One involved facilitation (of whole and component activities) and the other involved practice and facilitation of whole activities. Future research in which conventional or standard UK stroke physiotherapy is delivered should focus on these interventions and exclude atypically used interventions.
\end{abstract}

Keywords: Stroke, physiotherapy, posture, balance, mobility

\section{Introduction}

Clinical trials have shown stroke physiotherapy to be effective; however, many have been criticised for a lack of detail and clarity about the content of the physiotherapy intervention delivered [1]. This limits the impact of the research as it hampers replication, comparison between studies, the interpretation of outcomes and the application of findings into practice [2-6]. One reason for the lack of information about the content of physiotherapy is the complexity, multiplicity and variability of the techniques used, the way they are applied and the language used to describe them [7-9]. A number of different tools have been developed to address this issue by investigating the content of physiotherapy and occupational therapy $[6,10,11]$, physiotherapy alone $[12,13]$ and specific aspects of stroke physiotherapy, including positioning [14], shoulder pain [15], postural control and mobility $[9,16]$. These tools vary in the detail and manner in which the interventions are described and generally offer insufficient information for the interventions used to be replicated. Chatterton et al. [14] surveyed physiotherapists' perceptions of their practice and the aims of treatment rather than observing or recording their actual practice, whereas most other studies present information about the frequency with which groups of interventions (such as 'education of carer', 'exercise', 'equipment prescription' $[6,11,12]$ ) or the activity practiced (such as 'balance training' or 'transfers' [6,10-13]) were actually used during treatment sessions. Only Van Vliet et al. [13] and Tyson and Selley $[9,16]$ have attempted to

Correspondence: Sarah Tyson, Centre for Rehabilitation and Human Performance Research, Frederick Rd Campus, University of Salford, Salford M6 6PU, UK. Tel: 0161-295-7028. Fax: 0161-295-2963. E-mail: s.tyson@salford.ac.uk 
define and described the actual interventions used; Van Vliet et al. [13] by describing the type of activities that would be included in a category and Tyson and Selley $[9,16]$ by describing the individual interventions or group of techniques and how they are performed. However, merely counting the frequency with which interventions are used gives only a limited insight into the treatment process as interventions are often combined during a treatment session and are seldom used individually. This survey of selected UK National Health Service (NHS) trusts aimed to address this issue be exploring whether it was possible to identify combinations of physiotherapy interventions (treatment packages) for postural control and mobility problems in patients with stroke.

\section{Method}

\section{Design and procedure}

Participating physiotherapists were asked to record the content of their treatment sessions. The content of the treatment sessions was recorded using the Stroke Physiotherapy Intervention Recording Tool (SPIRIT) [9] which is a standardised published checklist of interventions used by physiotherapists to treat postural control and mobility problems after stroke. Interventions are divided into nine categories subdivided into individual interventions. The categories are: mobilisations, facilitation (whole activities and their components), practicing (activities and their components), exercise, teaching carers or professionals to assist patients, provision of equipment, organising independent practice and 'other'. Using published definitions and descriptions of interventions, therapists recorded the individual interventions used in each treatment session. The SPIRIT was originally developed in consultation with stroke physiotherapists from across Greater Manchester (UK) in 2001-2002 [9]; however, when the physiotherapists from the regions participating in the present study were consulted, some amendments to the layout were needed to represent all participants' views of the way they practiced. The changes were:

- The category 'preparation for practice' was removed and replaced with two separate categories; facilitation and mobilisations. The facilitation category was further sub-divided in to 'facilitation of whole activities' and 'facilitation of components of activities'. Facilitation of functional activities (such as transfers or bed mobility) and the components of functional activities (such as forward weight transfer as a component of standing up from sitting) were removed from 'practising functional activities' and added to the 'facilitation' category.

- The 'practice' category was also divided into 'practising whole activities' and 'practising the components of activities'.

- The definition of facilitation was altered to highlight that it could be a physically passive or active-assisted activity.

This revised version of the SPIRIT used in the present study can be obtained from the lead author (S.T.).

Guidance from the lead authors' Local Research Ethics Committee confirmed that ethical approval was not required for this study as physiotherapists were describing and recording normal practice without identifying any patient-specific data. Local trusts followed their local research governance procedures; permission was obtained from relevant departmental managers to conduct the survey.

\section{Inclusion and recruitment}

A convenience sample of stroke physiotherapists and their patients were recruited from NHS Trusts from across England, Wales and Northern Ireland. Participating physiotherapists were of any grade but needed to treat people with stroke at least once a week within any hospital-based setting. Information regarding the clinical setting in which the physiotherapists worked, their length of experience, job grade and the treatment concept they used was obtained. Each therapist completed the SPIRIT for at least five patients for five consecutive treatment sessions. All the patients were included so long as their treatment was primarily for a postural control problem (limited sitting balance, standing balance or stepping/walking). For each patient, therapists identified the primary postural control and mobility problem they were targeting with treatment, as well as other secondary aims, e.g. re-educating selective movement. As this was a pragmatic study, the authors' aim was to obtain a cross-section of 'real life' treatment, so patients were of any age, severity of stroke, stage of recovery, with any combination of comorbidity and stroke-related impairments were included. Physiotherapists were asked to select the patients and record the patients' treatment sessions 'as they came' and not to 'cherry pick' either the patients or the treatment sessions in any way.

The process of recruitment varied according to the resources and networks available in the different locations. In England, the network of neurological physiotherapists who had taken part in other studies led by the authors was contacted and other trusts 
were recruited by word of mouth and through personal contacts. In Wales and Northern Ireland, stroke physiotherapists were contacted through the physiotherapy managers' network.

\section{Analysis}

Descriptive statistics were used to describe the physiotherapists, patients and frequency with which interventions were used. The intervention categories and individual interventions were ordered with the most frequent interventions placed first.

Geometric coding was used to investigate the combinations of interventions used together (treatment packages). Each intervention category was designated a unique code from numbers in the sequence $a(n)=2^{n}(1,2,4,8,16,32, \ldots)$. This is a geometric progression that is a sum-free sequence which means that each number is never a sum of preceding numbers. Therefore, when the numbers are summated, there is only one combination of numbers that can be added together to add up to that number. Thus, the interventions that are used in combination in a treatment to give that geometric code can be identified. For example, the interventions 'facilitating whole activities' was coded as 1 , 'facilitating components of activities' was coded as 2 , 'mobilisations' was coded as 4 , etc. Thereafter, the numbers of interventions used in a treatment session were added together. For example, if 'facilitating whole activities', 'facilitating components of activities' and 'mobilisations' were used together in one treatment session they would be summated, giving a geometric code of 7 . The only possible combination of code numbers (interventions) that could give a geometric code of 7 is 4,2 and 1. To give another example, for a geometric code of 26 , the only possible combination would be 16,8 and 2 . This novel method of descriptive analysis enabled the most frequent combination of interventions or 'treatment packages' to be identified.

\section{Results}

\section{Physiotherapists}

Seventy-four physiotherapists from 34 hospitals used the SPIRIT to record their treatment. Their mean age was 30 (SD 6.8) years. Twenty-six per cent $(n=19)$ were junior physiotherapists, $27 \%(n=20)$ were senior IIs, $39 \%(n=28)$ senior Is and $8 \%$ $(n=6)$ were clinical specialists. The majority (47 physios, 65\%) worked in a rehabilitation setting. Most $(58 \%)$ based their treatment approach on the Bobath concept but also used other interventions (defined as 'Bobath eclectic'). Most of the remainder (37\%) defined their treatment approach as 'eclectic' meaning that they used a mixture of approaches and interventions. Only $5 \%$ classified their approach as 'Bobath purist' indicating that they never or rarely used methods other than the Bobath concept.

\section{Patients}

Data were collected for 251 patients, 106 were from hospitals in the North West of England (42\%), 81 were from Wales (32\%), 41 were from Northern Ireland (16\%), 17 were from Bristol $(7 \%)$ and six were from the Midlands (2\%). Their mean age was 71.4 (SD 14.1) years and median time since stroke was 3 weeks (IQR 1, 6 weeks with two outliers at 48 weeks and 10 years). One hundred one (40\%) patients had a right hemiplegia, $127(51 \%)$ had a left hemiplegia, $5(2 \%)$ had a bilateral stroke and the side was unrecorded for 18 patients $(7 \%)$.

\section{Aims and stage of therapy}

For $60(24 \%)$ patients, the primary aim of treatment was to restore sitting balance, for $86(34 \%)$ it was to restore standing balance and for $97(39 \%)$ it was to restore stepping/walking. The primary aim of treatment was unrecorded for eight $(3 \%)$ patients. The secondary aims were (in frequency order); to optimise alignment and postural adjustments $(n=116,46 \%)$, regain selective movements $(n=102,41 \%)$, practice a functional task $(n=75$, $30 \%)$, normalise tone $(n=54,22 \%)$ and prevent complications $(n=27,11 \%)$. Forty-seven (19\%) patients were in the acute stages of care or undergoing assessment, $180(72 \%)$ were undergoing rehabilitation and $21(8 \%)$ were pre-discharge. The stage of treatment was not recorded for three patients $(1 \%)$. Definitions of the stages of care are found in the Appendix.

\section{Interventions}

Data were collected for a total of 1156 therapy sessions during which 7343 interventions were used. The median number of interventions used per treatment session was 5 (IQR 3,8). Outlier values were obtained from nine physiotherapists who used 20-30 interventions in 23 treatment sessions and two physiotherapists who used over 30 interventions in 11 treatment sessions. The frequencies with which the interventions in the different categories were used are shown in Table I. The most frequently used interventions involved facilitation of whole activities 
Table I. Frequency with which interventions were used.

\begin{tabular}{|c|c|}
\hline & $n$ \\
\hline Facilitation (Total) & 4501 \\
\hline Facilitation of Whole Activity (Hands-On) & 2260 \\
\hline Sit-to-stand & 284 \\
\hline Static standing & 257 \\
\hline Dynamic standing & 256 \\
\hline Dynamic sitting & 236 \\
\hline Movement of the arm & 225 \\
\hline Walking with help & 210 \\
\hline Transfers & 184 \\
\hline Movement of the leg & 178 \\
\hline Static sitting & 157 \\
\hline Walking with aids & 138 \\
\hline Outdoor mobility & 31 \\
\hline Bed mobility & 75 \\
\hline Stairs & 23 \\
\hline Falls & 6 \\
\hline Facilitation of Components (Hands-On) & 1663 \\
\hline Movement of the arm & 305 \\
\hline Standing & 250 \\
\hline Movement of the leg & 231 \\
\hline Sit-to-stand & 227 \\
\hline Sitting & 224 \\
\hline Walking & 196 \\
\hline Transfers & 117 \\
\hline Bed mobility & 104 \\
\hline Stairs & 9 \\
\hline Falls & 0 \\
\hline Practising (Total) & 1612 \\
\hline Practising Whole Activities (Hands-Off) & 1014 \\
\hline Dynamic standing & 129 \\
\hline Walking with aids & 118 \\
\hline Sit-to-stand & 114 \\
\hline Free walking & 104 \\
\hline Dynamic sitting & 85 \\
\hline Static sitting & 78 \\
\hline Transfers & 73 \\
\hline Static standing & 69 \\
\hline Movement of the leg & 51 \\
\hline Movement of the arm & 51 \\
\hline Bed mobility & 36 \\
\hline Stairs & 34 \\
\hline Outdoor mobility & 11 \\
\hline Treadmill & 7 \\
\hline Wheelchair skills & 6 \\
\hline Practising Components of Activities (Hands-Off) & 598 \\
\hline Movement of the leg & 95 \\
\hline Movement of the arm & 93 \\
\hline Standing & 82 \\
\hline Walking & 81 \\
\hline Sit-to-stand & 84 \\
\hline Sitting & 60 \\
\hline Transfers & 54 \\
\hline Bed mobility & 28 \\
\hline Stairs & 14 \\
\hline Falls routine & 5 \\
\hline Wheelchair skills & 2 \\
\hline Mobilisations & 578 \\
\hline Shoulder girdle mobilisations & 164 \\
\hline Trunk mobilisations & 144 \\
\hline Specific muscle mobilisations & 142 \\
\hline Specific joint mobilisations & 128 \\
\hline Organising independent practice & 492 \\
\hline Sit-to-stand & 98 \\
\hline
\end{tabular}

(continued)
Table I. (Continued).

\begin{tabular}{lr} 
& \\
& $n$ \\
\hline Strengthening exercises & 94 \\
Stretching exercises & 69 \\
Walking indoors & 68 \\
Transfers & 66 \\
Bed mobility & 49 \\
Outdoor mobility & 16 \\
Cardiovascular exercises & 15 \\
Stairs & 11 \\
Resisted exercises & 6 \\
Exercises & 289 \\
Stretching exercises/passive movements & 117 \\
Strengthening exercises & 130 \\
Cardiovascular fitness exercises & 24 \\
Resisted exercise & 18 \\
Teaching carers/HCPs & 271 \\
Positioning & 82 \\
Transfers & 63 \\
Walking indoors & 58 \\
Stretching & 17 \\
Use of ankle foot orthoses/splints & 13 \\
Use of manual handling equipment & 11 \\
Wheelchair skills & 10 \\
Bed mobility & 8 \\
Outdoor mobility & 5 \\
Stairs & 105 \\
Other & 35 \\
Sensory stimulation & 24 \\
Postural perturbations & 20 \\
Other & 36 \\
Gym ball & 21 \\
Providing or training patient in the use of & 21 \\
Walking aids & 11 \\
Transfer/manual handling equipment & \\
Ankle foot orthoses & \\
Other splints, e.g. wrist splints & \\
Wheelchair skills & \\
\hline & \\
\hline
\end{tabular}

$(n=2260)$ and components of activities $(n=1663)$ followed by practice of whole activities $(n=1014)$, practice of components of activities $(n=598)$ and mobilisations $(n=578)$. The most frequently facilitated whole activities were (in frequency order) sit to stand, standing, sitting, movements of the arm and walking. The most frequently practised whole activities were standing, walking with aids, sit to stand and free walking. Shoulder girdle mobilisations were the most frequently used type of mobilisation.

The least frequently used interventions involved the provision of equipment $(n=161)$, teaching carers or professionals $(n=271)$, exercise $(n=289)$ and arranging independent practice $(n=492)$. Interventions involving outdoor mobility, falls routines, stairs, wheelchairs skills, bed mobility or treadmills were rarely used. The most common activities for independent practice were sit to stand, walking indoors, transfers and bed mobility. Stretching and strengthening exercises were the most frequently used exercise intervention, with cardiovascular and resisted exercise rarely used. 
In the 1156 recorded treatment sessions, 196 different combinations of interventions were used. The most frequent treatment package combined facilitation techniques; 'facilitating whole activities' and 'facilitating the components of movements', which were used together in $588(51 \%)$ of treatment sessions. This treatment package was used without any other interventions in 108 (9\%) treatment sessions. It was also used with the following interventions:

- mobilisations in 252 sessions

- practicing components of movements in 197 sessions

- practising whole activities in 168 sessions

- exercise in 129 sessions

- independent practice in 121 sessions

- teaching carers or professionals in 111 sessions

- provision of equipment in 76 sessions

The second most frequent treatment package combined 'facilitating whole activities' with 'practicing whole activities', which were used together in 262 sessions (23\%). This package was used without any other interventions in 39 sessions (3\%) and was also used in conjunction with the following interventions:

- facilitating components of movements in 164 sessions

- practicing components of movements in 126 sessions

- mobilisations in 89 sessions

- independent practice in 72 sessions

- exercise in 72 sessions

- teaching carers or professionals in 53 sessions

- provision of equipment in 41 sessions

The least used interventions were: mobilisations, arranging independent practice, exercise, teaching carers/health care professionals and provision of equipment. These were only used without facilitation or practice interventions in 45 treatment sessions; 13 treatment sessions for exercise, nine treatment sessions for arranging independent practice, seven for teaching carers/health care professionals and just two for the provision of equipment.

\section{Discussion and conclusion}

The results of this study show that UK physiotherapists most frequently use therapist-led facilitation techniques in preference to interventions that require the patient to move independently, such as practicing tasks. They focus on walking and basic mobility such as sit-to-stand and balance. Other aspects of mobility such as bed mobility, walking outdoors or wheelchair skills are less frequently addressed. Interventions involving exercise, independent practice of activities, teaching others to assist the patient or using equipment are rarely used. Interventions were seldom used in isolation; they were usually combined into treatment packages. Two main treatment packages were identified. One involved facilitation techniques often combined with mobilisations. The other involved facilitation and practice of whole activities often combined with the components of activities. The less-favoured interventions (independent practice, exercise and the use of equipment) were almost invariably used with these two treatment packages. These results indicate that if a UK-based clinical trial of physiotherapy for postural control and/or mobility was to involve 'conventional', 'normal' or 'standard' treatment, it should include facilitation, practice and mobilisation interventions but exclude the less frequently used (and therefore atypical) interventions such as exercise, use of equipment and arranging independent practice.

The results of the present study show many similarities with a previous study to measure the content of stroke physiotherapy some 5 years earlier [16], but there were also some differences which suggest a trend toward changes in practice. In this study, as previously, the main focus of treatment was on therapist-led interventions to normalise movement patterns and reduce muscle tone (facilitation, mobilisations and practicing the components of tasks) which are reflected in the physiotherapists' secondary aims of treatment. However, mobilisations are now used less frequently and whole tasks are practised more frequently suggesting some movement towards greater patient activation and a focus on function during therapy sessions. Although encouraging, this does not translate in to direction for patients to be active or independent outside the treatment session as the use of independent practice of tasks is unchanged, whereas teaching others to assist patients has decreased and the provision of equipment are still the least used interventions. This is contrary to the recommendations of the National Clinical Guidelines for Stroke [17] which state that the skills gained within therapy should be integrated in the patients' daily life. To achieve this, therapists need to place greater emphasis on encouraging patients to be active and to practice independently outside therapy sessions.

The use of exercise has increased since our first survey [16] due to more frequent use of strengthening exercises. This suggests some movement towards a systems model approach which addresses all motor impairments including muscle weakness and range of movement [18]. However, the most frequently used interventions aim to normalise movement patterns and muscle tone/spasticity which is reflected in the secondary aims of treatment indicating that 
physiotherapists still prioritise them over weakness. This is despite the growing body of evidence to show that a minority of stroke patients actually have spasticity and that is not clearly related to function [19], and the strong evidence that weakness is intimately related to function and recovery [20].

Most of the participants in this study stated that their practice was based on the Bobath concept, but there is a striking contrast between the way in which the physiotherapists practiced the concept and the perceptions of how it should be delivered expressed by its gate-holders; the British and International Bobath tutors [21-23]. For example, the participants predominantly use interventions to normalise the movement patterns and muscle tone, but the British Bobath tutors currently give primacy to restoring efficiency of movement [23] and the international tutors emphasise the importance of weakness and adaptive features of the upper motor neuron syndrome [21]. This indicates that the position documents stating how the Bobath concept has evolved in recent years [21-23] have not been adopted into mainstream clinical practice and further illustrates the previously reported discrepancies between the way in which the Bobath concept is operationalised in everyday clinical practice and the current beliefs of the Bobath experts about how it should be practised [16].

The study has a number of limitations. Although we included participants from across the UK, we were not able to recruit physiotherapists from Scotland and the North-East and South-East of England - some of the most populous areas. It is possible that the physiotherapists from the nonsurveyed areas practiced differently. Notwithstanding this, the physiotherapists in this study provided stroke care for a population of approximately 12 million people and include a typical skill mix, so we feel are fairly representative and generalisable to the UK. It was not possible to compare practice between the different sites or of participants who used different treatment approaches as the small numbers of participants in some sites made such comparisons unfeasibly under-powered.

Declaration of interest: The authors report no conflicts of interest. The authors alone are responsible for the content and writing of the paper.

\section{References}

1. Pomeroy V, Tallis R. Neurological rehabilitation: A science struggling to come of age. Physiother Res Int 2002;7:76-89.

2. Lennon S. Physiotherapy practice in stroke rehabilitation: A survey. Disabil Rehabil 2003;25:455-461.

3. Pollock A, Baer G, Pomeroy V, Langhorne P. Physiotherapy treatment approaches for the recovery of postural control and lower limb function following stroke. [update of Cochrane Database Syst Rev 2003;2:CD001920; PMID: 12804415]. Cochrane Database Syst Rev 2007:CD001920.

4. Wade D. Barriers to rehabilitation research, and overcoming them. Clin Rehabil 2003;17:1-4.

5. Partridge C. Evaluation of physiotherapy for people with stroke. London: Kings Fund, 1994.

6. Ballinger C, Ashburn A, Low J, Roderick P. Unpacking the black box of therapy - A pilot study to describe occupational therapy and physiotherapy interventions for people with stroke. Clin Rehabil 1999;13:301-309.

7. Marsden J, Greenwood R. Physiotherapy after stroke: define, divide and conquer. J Neurol Neurosurg Psychiatry 2005;76: 465-466.

8. Pomeroy VM, Tallis RC. Need to focus research in stroke rehabilitation. Lancet 2000;355:836-837.

9. Tyson S, Selley A. The development of the stroke physiotherapy intervention recording tool (SPIRIT). Disabil Rehabil 2004;26:1184-1188.

10. De Wit L, Kamsteegt H, Yadav B, Verheyden G, Feys H, De Weerdt W. Defining the content of individual physiotherapy and occupational therapy sessions for stroke patients in an inpatient rehabilitation setting. Development, validation and inter-rater reliability of a scoring list. Clin Rehabil 2007;21: 450-459.

11. Dejong G, Horn S, Gassaway J, Slavin $M$, Dijkers $M$. Towards a taxonomy of rehabilitation interventions: Using an inductive approach to examine the 'black box' of rehabilitation. Arch Phys Med Rehabil 2004;85:678-686.

12. Jette DU, Latham NK, Smout RJ, Gassaway J, Slavin MD, Horn SD. Physical therapy interventions for patients with stroke in inpatient rehabilitation facilities. Phys Ther 2005;85: 238-248.

13. van Vliet PM, Lincoln NB, Robinson E. Comparison of the content of two physiotherapy approaches for stroke. Clin Rehabil 2001;15:398-414.

14. Chatterton H, Pomeroy V, Gratton J. Positioning for stroke patients: A survey of physiotherapist's aims and practices. Disabil Rehabil 2001;23:413-421.

15. Pomeroy VM, Niven DS, Barrow S, Faragher EB. Unpacking the black box of nursing and therapy practice for post-stroke shoulder pain: A precursor to evaluation. Clin Rehabil 2001;15:67-83.

16. Tyson S, Selley A. A content analysis of physiotherapy for postural control in people with stroke: An observational study. Disabil Rehabil 2006;28:865-872.

17. Royal College of Physicians. National clinical guidelines for stroke. Prepared by the Intercollegiate Stroke Working Party, 2nd ed. London: Royal College of Physicians, 2004.

18. Shumway-Cook A, Woollacott M. Motor control: Translating research into clinical practice, 3rd ed. Philadelphia: Lippincott Williams \& Wilkins, 2006.

19. Sommerfield D, Eek E, Svensson A, Holmquist L, von Arbin M. Spasticity after stroke: Its occurence and association with motor impairments and activity limitations. Stroke 2004; 35:134-139.

20. Tyson SF, Chillala J, Hanley M, Selley A, Tallis R. The relationship between balance, disability and recovery after stroke: Predictive validity of the Brunel Balance Assessment. Neurorehabil Neural Repair 2007;21:341-346.

21. International Bobath Instructors Training Association. Theoretical assumptions and clinical practice. Internet. 2007. Electronic Citation. http://www.ibita.org/. Last accessed October 2007.

22. Raine S. Defining the Bobath concept using the Delphi technique. Physiother Res Int 2006;11:4-13.

23. Raine S. The current theoretical assumptions of the Bobath concept as determined by the members of BBTA. Physiother Theory Pract 2007;23:137-152. 


\section{Appendix: Stages of physiotherapy}

These stages are defined by the physiotherapist for each individual patient. They refer to the stage of physiotherapy not the time since stroke or the treatment facility. So a patient could be in the assessment stage weeks or months after a stroke, e.g. if they have just been transferred to the rehabilitation unit or if their condition has been fluctuating because they are medically unstable or very unwell. Equally, they could be in the rehabilitation stage while still on an acute unit.

\section{Acutelassessment phase}

A period when the physiotherapist/stroke team are primarily gathering information about the patient identifying impairments and disability, assessing the social and personal context and environment, monitoring response to treatment, etc. In most cases, this would be short-lived stage - a few days usually following admission, either to an acute ward following the stroke or transfer to a rehabilitation unit.

\section{Rehabilitation phase}

During this phase, the main aim for the patient is to undergo treatment to maximise movement-related ability/function. The physiotherapist aims to achieve this by delivering interventions which aim to reduce impairments and disability.

\section{Pre-discharge phase}

The patient is being prepared for discharge from the in-patient facility. A discharge destination has been identified and physiotherapy is geared towards enabling the patient to manage safely and as independently as possible within that environment. A discharge date may or may not have been set. 